\title{
Delayed two-stage nipple sparing mastectomy and simultaneous expander-to-implant reconstruction of the large and ptotic breast
}

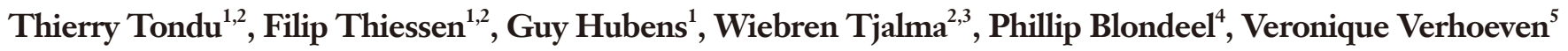 \\ ${ }^{1}$ Department of Abdominal, Pediatric and Reconstructive Surgery, Plastic Surgery Unit, Antwerp University Hospital, Antwerp, Belgium; \\ ${ }^{2}$ Multidisciplinary Breast Clinic, Unit of Gynecologic Oncology, Antwerp University Hospital, Antwerp, Belgium; ${ }^{3}$ Department of Obstetrics \\ and Gynecology, Antwerp University Hospital, Antwerp, Belgium; ${ }^{4}$ Department of Plastic Surgery, Ghent University Hospital, Ghent, Belgium; \\ ${ }^{5}$ Department of Family Medicine and Population Health, Faculty of Medicine and Health Sciences, University of Antwerp, Antwerp, Belgium \\ Contributions: (I) Conception and design: T Tondu, F Thiessen, W Tjalma, P Blondeel; (II) Administrative support: G Hubens, V Verhoeven, W \\ Tjalma, P Blondeel; (III) Provision of study materials or patients: W Tjalma, P Blondeel; (IV) Collection and assembly of data: T Tondu; (V) Data \\ analysis and interpretation: T Tondu, F Thiessen, G Hubens, V Verhoeven; (VI) Manuscript writing: All authors; (VII) Final approval of manuscript: \\ All authors. \\ Correspondence to: Thierry Tondu, MD. Department of Abdominal, Pediatric and Reconstructive Surgery, Plastic Surgery Unit, Antwerp University \\ Hospital, Drie Eikenstraat 655, 2650 Edegem, Antwerp, Belgium. Email: t.tondu@clinic12b.be.
}

Background: Large and ptotic breasts are considered an anatomical contraindication for nipple sparing mastectomy (NSM). Necrosis rates can be as high as $76 \%$. The authors examined whether targeted preshaping mastopexy/reduction combined with simultaneous two-stage preshaping of the implant pocket prepares for an uneventful implant reconstruction.

Methods: Macromastia and ptosis patients opting for risk-reducing NSM or having a peripherally localized carcinoma in situ, were offered a two-stage mastopexy/reduction simultaneously with preshaping of the implant pocket by subpectoral expansion. Only the inferior pedicle bearing the nipple-areola complex (NAC), remained. A delayed secondary NSM and tissue expander-to-implant reconstruction was scheduled 3 months later. The use of an acellular dermal matrix (ADM) was not necessary because the capsule around the expander created a hammock supporting the definite prosthesis. Follow up was at 2 weeks, 3 months, and 6 months.

Results: Forty-one procedures were performed in 24 patients. The mean age was $45 \pm 12.08$ years (range, 22 to 72 years). Patients' mean body mass index (BMI) was $26.79 \mathrm{~kg} / \mathrm{m}^{2}$ (range, 19 to $35 \mathrm{~kg} / \mathrm{m}^{2}$ ). One patient had diabetes and two smoked. One transient epidermolysis of the NAC occurred in each stage. No NAC or skin necrosis occurred; no implant had to be removed.

Conclusions: A two-stage mastopexy/reduction, simultaneously with preshaping of the implant pocket by tissue expansion and followed by a 3-month delayed secondary NSM with tissue expander-to-implant reconstruction is a safe technique in large ptotic breasts.

Keywords: Nipple sparing mastectomy (NSM); nipple delay; nipple necrosis; delayed breast reconstruction; breast preshaping

Submitted Nov 05, 2021. Accepted for publication Jan 28, 2022.

doi: $10.21037 /$ gs-21-734

View this article at: https://dx.doi.org/10.21037/gs-21-734 


\section{Introduction}

Nipple sparing mastectomy (NSM) in large breasts with important ptosis is still considered a relative to absolute contraindication because of the increased risk of nippleareola complex (NAC) necrosis. Since Palmieri (1) described the principle of staged nipple delay in 2005, two major approaches have been developed trying to secure perfusion. The idea of delaying the NAC by circumareolar dermal perfusion in larger breasts by Jensen in 2012 (2) has gained popularity after Jolie's bilateral risk-reducing procedure (3). In the same year, Spear et al. (4) proposed a technique of preshaping the breast by a staged circumareolar dermal mastopexy before NSM. However, NAC perfusion is also kept on a large, mainly superior glandular pedicle and only a small reduction is added in the first stage. In 2013, Alperovich et al. (5) and Vaughn et al. (6) targeted the reliability of reperfusion through existing circumareolar scars by performing NSM in patients with a history of breast reduction with Wise pattern incisions. Until 2016 the focus remained on circumareolar dermal perfusion. Only Spear (4) focused on the absolute importance of only superior dermal supply. Schwartz et al. (7) combined the idea of delayed dermal NAC perfusion with the delay of an inferior NAC bearing dermal pedicle. Delaying the NAC on a pedicled approach makes NAC repositioning easier and more reliable in a second stage. Our preliminary study in 2016 described a fixed inferior pedicle approach using a first stage glandulodermal delay of the NAC followed by an immediate bilateral prosthesis reconstruction (8). In 2017, Gunnarsson et al. (9) used the preshaped principle where the NAC is supplied by a dermoglandular central, superior or superomedial pedicle. Recent review shows tendence of less necrosis in a staged NSM approach (10). In this study we combine preshaping of the breast with NAC delay on an inferior dermoglandular pedicle, together with preshaping of the definite submuscular prosthesis pocket by tissue expansion in two stages. The aim of this study is to examine whether targeted preshaping mastopexy/reduction combined with simultaneous two-stage preshaping of the implant pocket prepares for an uneventful implant reconstruction.

We present the following article in accordance with the STROBE reporting checklist (available at https:// gs.amegroups.com/article/view/10.21037/gs-21-734/rc).

\section{Methods}

We reviewed all patients with large (cup-size C and larger) and/or ptotic (Regnault ptosis grade 2 and 3) from January 2010 to June 2018. All patients underwent a staged risk-reducing NSM or NSM as a definite treatment for peripheral early non-invasive breast cancer [ductal carcinoma in situ (DCIS), and lobular carcinoma in situ (LCIS)]. Although several patients also had an indication for autologous reconstruction, they opted for a prosthesis reconstruction because of length of surgery, absence of donor scars, no donor site morbidity and a shorter recovery period. The tumor-free margin to the NAC had to be more than $2 \mathrm{~cm}(11,12)$. All patients underwent clinical follow-up and radiological imaging on regular basis.

The study population included 24 patients with large and/or ptotic breasts who underwent a delayed twostage procedure NSM and bilateral expander/prosthesis reconstruction. Seven patients had a unilateral procedure (because of an earlier contralateral mastectomy), 17 bilateral. Nine patients had a strong positive family history for breast cancer, 13 patients had a genetic predisposition (nine patients were BRCA1 mutation carriers, three BRCA2, and one CDH1) and two had fibrocystic mastopathy. No patients were diagnosed with suspect imaging prior to inclusion. The mean age was $45 \pm 12.08$ years (range, 22 to 72 years). Mean body mass index (BMI) was $26.68 \mathrm{~kg} / \mathrm{m}^{2}$ (range, 19 to $35 \mathrm{~kg} / \mathrm{m}^{2}$ ). Cup size varied from $\mathrm{C}$ to $\mathrm{G}$. On average sternal nipple index (SNI) was $29.3 \mathrm{~cm}$ (range, 24 to $38 \mathrm{~cm}$ ). Six breasts had Regnault ptosis degree 2 and 35 breasts had degree 3. One patient had diabetes and two smoked. Three bilateral patients underwent a margin-free lumpectomy with negative sentinel node biopsy for peripheral DCIS in one of the treated breasts prior to inclusion for staged NSM. The three specimens showed low, intermediate, and high nuclear grade DCIS. They opted for NSM as a definitive treatment instead of adjuvant radiation therapy after lumpectomy. The other 38 procedures were risk-reducing.

The Ethics Committee of the Antwerp University Hospital, Antwerp, Belgium approved this research (19/26/314). Patients gave their written informed consent to participate in the study, and for publication of photos. The study complied with the principles of the Declaration of Helsinki (as revised in 2013).

\section{Surgical technique}

In the first stage, an inferior pedicle breast reduction with Wise pattern skin reduction was performed (Figure 1) (13). The inferior pedicle has a width of $6 \mathrm{~cm}$ and preserves 


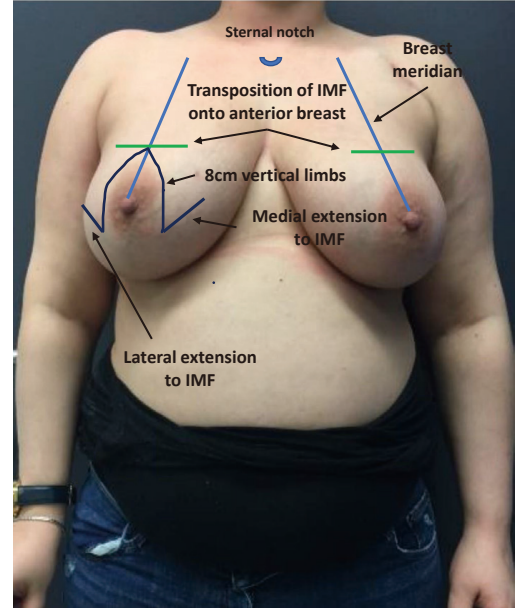

Figure 1 Preoperative markings. We use an inferior dermoglandular pedicle width of $6 \mathrm{~cm}$ in a classic Wise-pattern design. The NAC is positioned at the level of the transposition of the IMF (13). NAC, nipple-areola complex; IMF, inframammary fold.

the anterior intercostal branches 4 to 6 originating from the internal thoracic artery (14). We aimed for a maximal glandular volume reduction and appropriate size reduction of the skin envelope. The breast gland, besides the pedicle, is removed by scissors as in a subcutaneous mastectomy with infiltration of $0.5 \%$ of lidocaine and $1: 200,000$ epinephrine mixture, focusing on the dissection plane. The NAC was repositioned on the same level as the onset of the medial inframammary fold (IMF). In the first stage the glandular resection together with the skin excision was performed "en bloc". The specimen was specifically marked to be able to locate unexpected malignancies in those predisposed patients. During the same procedure, an anatomical tissue expander (Mentor CPX4 Contour Profile Breast Tissue Expanders) was placed subpectorally. The expander is inserted through the lateral pectoral border and is completely covered by muscle. The inferior border and medial lower $1 / 3$ of the pectoral muscle are released. After insertion, the expander is filled with $120 \mathrm{cc}$ of saline.

In the second stage, resection of the remaining glandular pedicle was carried out through the vertical part of the anchor pattern. The incision could be extended either medially or laterally to the NAC on the already existing periareolar scar. NSM of the remaining glandular pedicle was scheduled at least 3 months after the first stage. This delay was acceptable because of the risk-reducing nature of the procedure. Positive DCIS lumpectomy margins were no indication for this technique, but an indication for skin- sparing mastectomy (SSM) with NAC resection: further resection would compromise the NAC vascular supply and create an increased risk of NAC involvement. In case of DCIS removal with free margins in three breasts, the 3 -month delay between both stages was also acceptable. In the same procedure the expander is replaced by a definite subpectoral prosthesis (Figures 2,3).

Retroareolar sampling was performed in the second stage. It was impossible to perform sampling in the first stage without compromising vascular NAC supply. While resecting the glandular part of remaining NAC bearing pedicle, the retroareolar area was specifically marked on the pathology specimen. In case of positive retroareolar sampling a SSM would have been performed together with NAC resection. Early breast cancer patients with tumorfree margins less than $2 \mathrm{~cm}$ to the NAC on preoperative MRI imaging were excluded from this technique: they were not candidates for NSM because of the potential risk of positive NAC margins.

The classic inferior pedicle breast reduction approach in our technique creates a wide exposure of the complete breast gland, even the axillary tail can be properly approached in the first stage. Nevertheless, glandular tissue will occur outside the dissection plane, in NSM as well as in classic mastectomy (15). The risk of finding terminal duct lobular units strongly increased for skin flaps thicker than $5 \mathrm{~mm}$ (16). In a study by van Verschuer, 21 primary breast cancers occurred after 6,044 prophylactic mastectomies. Of these, three occurred after a total mastectomy $(0.6 \%$ of all total mastectomies), 17 occurred after a conservative mastectomy ( $0.3 \%$ of all subcutaneous mastectomies, NSM or SSM) in 24 studies (17). van Verschuer points out that the majority of primary breast cancers did not originate near the NAC or skin flap.

\section{Results}

All 24 patients (41 breast procedures) underwent a planned delayed two-stage NSM and simultaneous expander to implant reconstruction. The average resection weight (RW) in the first stage was $438.20 \mathrm{~g}$ (range, 180 to $1,305 \mathrm{~g}$ ) and in the second stage $185.23 \mathrm{~g}$ (range, 95 to $589 \mathrm{~g}$ ). The overall amputation weight was $623.76 \mathrm{~g}$ (range, 296 to $1,894 \mathrm{~g})$. The average filled expander volume (EV) was $396.3 \mathrm{cc}$ (range, 250 to $550 \mathrm{cc}$ ) (Table 1). The mean time between the first and second procedure was $6 \pm 2.26$ months (range, 3 to 12 months). The perfusion of the NAC and the skin flaps was assessed clinically. In the first stage pathology 

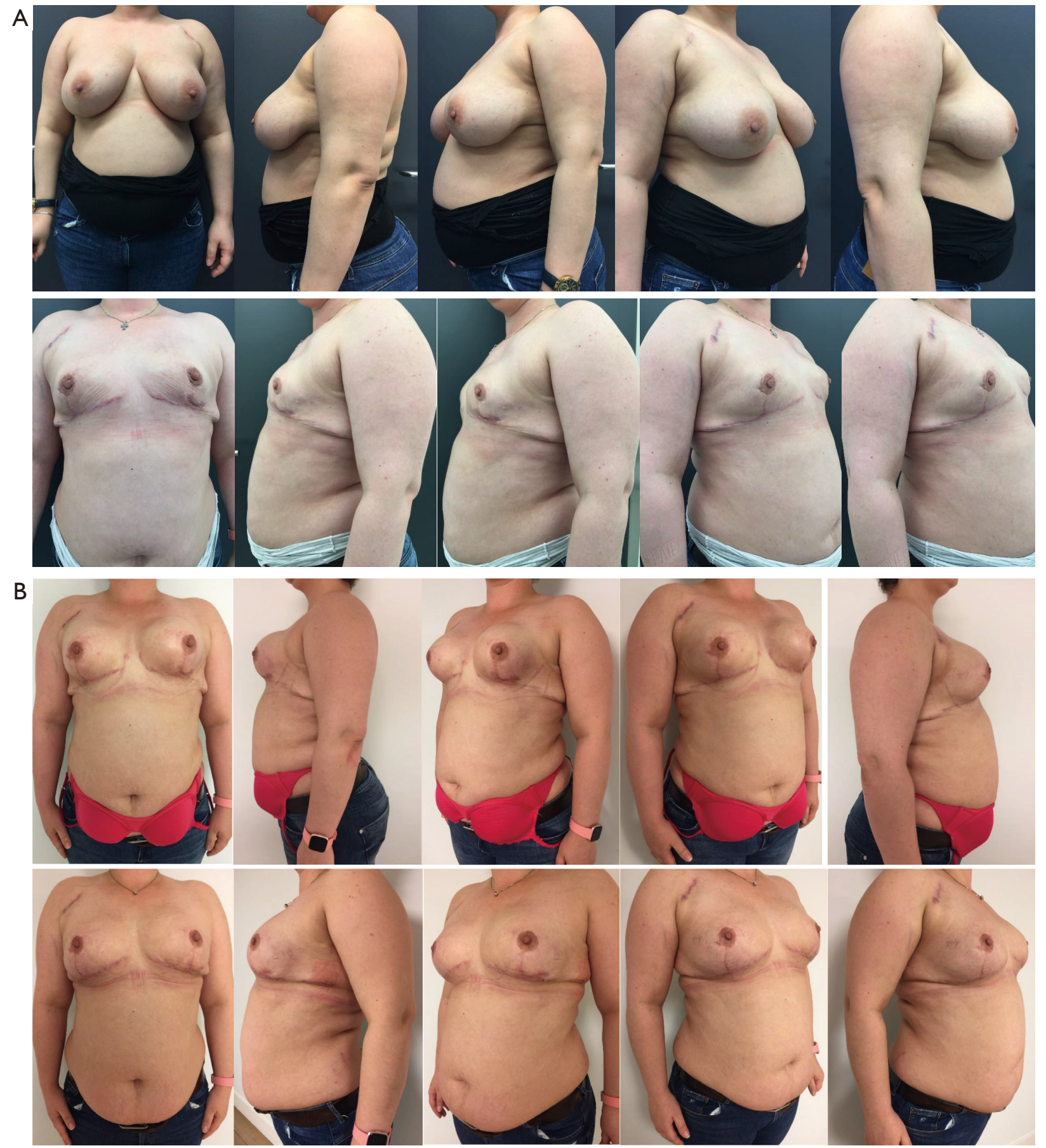

Figure 2 Frontal, 3/4 and lateral views of a risk-reducing bilateral staged procedure preoperatively and respectively 6 weeks after the first (A) and the second stage (B). (A) Frontal, 3/4 and lateral views preoperatively and 6 weeks postoperatively following the first stage in a risk-reducing bilateral staged procedure. The tissue expanders are placed subpectorally after an extensive "en bloc" breast and skin reduction. The right subclavicular port-a-cath was removed during the first stage. The lateral part of the left inframammary incision had a prolonged healing period due to epidermolysis with spontaneous healing. (B) Frontal, 3/4 and lateral views preoperatively and 6 weeks postoperatively following second stage in a risk-reducing bilateral staged procedure. The tissue expanders are replaced by a definite prosthesis and the inferior dermoglandular pedicle is resected through the vertical part of the Wise-pattern. The lateral part of the left inframammary incision had a prolonged healing period due to epidermolysis with spontaneous healing. 

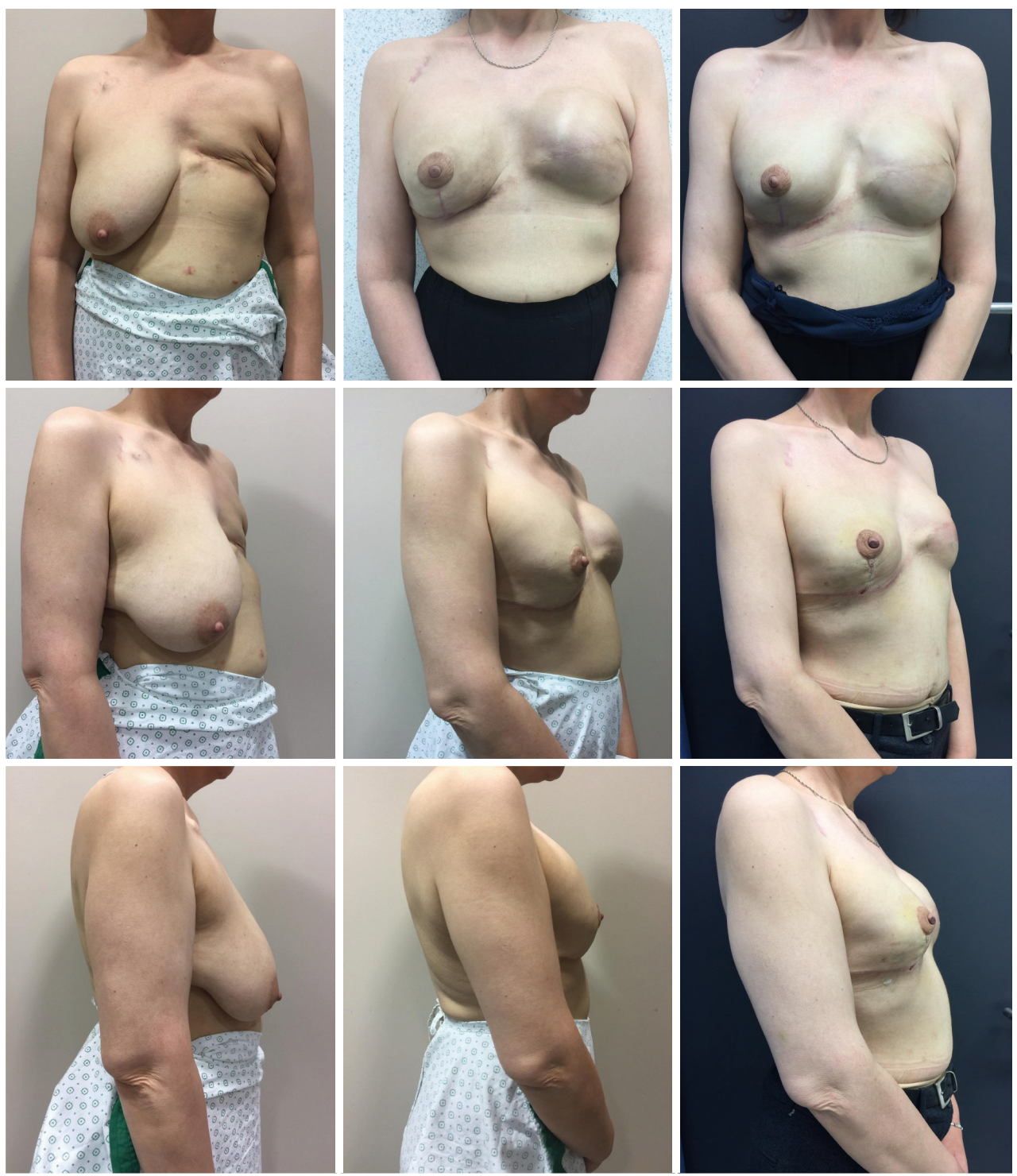

Figure 3 Frontal, 3/4 and lateral views preoperatively, 3 months following the first stage and 3 months following the second stage in a riskreducing unilateral staged procedure of the right breast. The right subclavicular port-a-cath was removed during the first stage. The patient also underwent a secondary reconstruction at the left breast by tissue expansion followed by a definite prosthesis.

showed three classical type LCIS and two DCIS (both low grade) in four patients (one bilateral LCIS in a BRCA1 patient) and fibrocystic mastopathy in five patients. In accordance with the guidelines of the American Society of Clinical Oncology (ASCO), no sentinel node biopsy was performed (18). In the second stage, one intraductal papilloma was found as well as five fibrocystic mastopathies. In three patients with DCIS lumpectomy the same procedure was followed within 3 months after the first stage. In the second stage, 41 anatomical tissue expanders were replaced by
29 textured anatomical (20 Groupe Sebbin SAS anatomical LSA TF tall height full projection prostheses and nine Groupe Sebbin SAS LSA TM tall height moderate projection prostheses) and 12 round microtextured prostheses (eight Groupe Sebbin SAS LS 71 high profile and four Groupe Sebbin SAS LS 70 moderate profile prostheses). The average prosthesis volume was $479 \mathrm{cc}$ (range, 300 to $600 \mathrm{cc}$ ). We noted ten complications in 41 procedures. Three breasts (two active smokers) had epidermolysis of part of the skin envelope (distal inverted $\mathrm{T}$ scar). In the first stage, one of these two 
Table 1 BMI, RW in stages 1 and 2, final EV and of the definitive IV

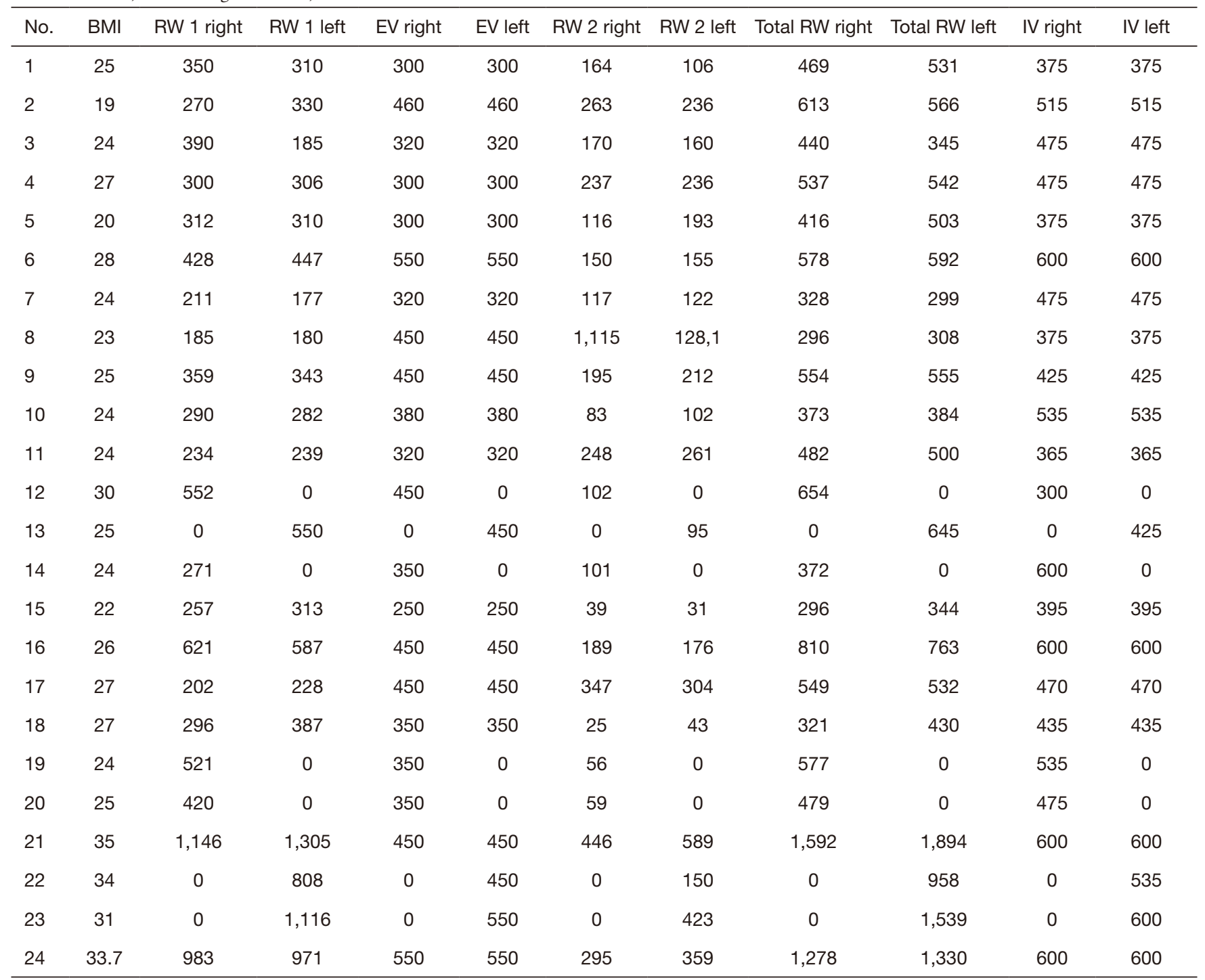

0 is a unilateral procedure, 1 and 2 are stage 1 and stage 2. BMI, body mass index; RW, resection weight; EV, expander volume; IV, implant volume.

active smokers also had complete NAC epidermolysis. In the second stage, one patient had epidermolysis of the NAC left upper quadrant. All four patients with epidermolysis recovered with conservative therapy. No necrosis of the NAC or skin envelope was noted. In our study, three out of five reports of epidermolysis occur in the only two smoking patients (one of these two patients has a complete epidermolysis of NAC as well as an epidermolysis of the distal skin flap at the inverted T-point). Two infections of the skin envelope recovered completely with oral antibiotics. Three hematomas resolved spontaneously with prolonged bruising (Table 2: complications per procedure). The final $\mathrm{S}-\mathrm{N}$ was $24.04 \mathrm{~cm}$ (range, 22 to $27 \mathrm{~cm}$ ) with a cup-size range of $\mathrm{C}$ to D. Follow up ranged from 4 to 11 years, after the second stage. Neither locoregional recurrences nor distant metastasis were reported. One vertical scar correction and one capsuloraphy for lateral prosthesis displacement were performed. Three implants needed replacement: two because of a bilateral Baker IV capsular contracture and one because of an early implant rupture. Two bilateral implants were removed because of discomfort and replaced by a bilateral autologous reconstruction. 
Table 2 Patient characteristics and complication rates in two stages

\begin{tabular}{|c|c|c|c|c|c|c|c|}
\hline Type & $\begin{array}{l}\text { No. of } \\
\text { patients }\end{array}$ & $\begin{array}{l}\text { No. of } \\
\text { breasts }\end{array}$ & $\begin{array}{l}\text { Average time from reduction } \\
\text { to NSM (months) }\end{array}$ & Infection & Epidermolysis NAC & $\begin{array}{l}\text { Epidermolysis skin } \\
\text { envelope }\end{array}$ & Hematoma \\
\hline Prophylactic $(\mathrm{n}=38)$ & 21 & 38 & 6 & 2 & 2 & 3 & 2 \\
\hline Total complications & NA & NA & NA & 2 & 2 & 3 & 3 \\
\hline
\end{tabular}

DCIS, ductal carcinoma in situ; NSM, nipple sparing mastectomy; NAC, nipple-areola complex; NA, not applicable.

\section{Discussion}

In our study, no necrosis of the NAC or skin envelope was noted following forty-one procedures. The unreliability of the blood supply to the NAC and skin envelope in large breasts is based on several surgery related and non-related factors (10). The length of the skin flap correlates with terminal blood supply in this most remote part of the flap $(19,20)$. To obtain a natural breast shape, extra skin incisions will also reduce dermal blood flow $(21,22)$. This explains why we can expect more skin necrosis in NSM and SSM in large and ptotic breasts (23). We specifically avoid reusing the inframammary incision: the dermal vascular supply to the skin superior to the inframammary scar is much longer than the vascular supply to the vertical component.

A significant correlation exists between removed glandular volume and an increase in necrosis: in Chirappapha's study of 124 NSM, patients with a breast resection volume larger than $750 \mathrm{~cm}^{3}$ have $23 \%$ NAC necrosis compared to 6\% NAC necrosis in less than $750 \mathrm{~cm}^{3}$ of removed breast volume $(\mathrm{P}<0.01)$ (24). Moreover, there is no single specific universal thickness for mastectomy skin flaps since the thickness of the subcutaneous layer varies between individuals (25). Dissection in the correct anatomical plane is mandatory. Preshaping of the skin envelope allows reduction of the prosthesis volume. This will reduce traction on the skin flaps to restore the breast mound $(11,12)$. Surgery non-related risks include age, diabetes, smoking, prior irradiation, and BMI $(21,24)$. These variables are also risk factors for vascular insufficiency and flap necrosis (26).

NAC and skin flap evaluation in our study is only performed clinically, based on color and capillary refill. An additional tool in assessment of skin flap and NAC viability is the intraoperative use of near-infrared fluorescence angiography (27). Indocyanine green (ICG) was used as fluorescence dye. ICG angiography qualitatively shows the presence of dermal perfusion in real-time (28). Gorai et al. show a significant decrease in full thickness necrosis from $17.8 \%$ to $4.8 \%$ with the use of ICG angiography-guided skin trimming (29). In pedicled perforator flaps or for large skin paddles, intraoperative ICG angiography is strongly correlated with postoperative outcomes (30).

NAC involvement in local recurrence is uncommon (31-34). We advocate a $2 \mathrm{~cm}$ tumor-free margin to the NAC (35). NSM is recommended for risk reducing surgery as well as a good alternative for the treatment of early breast cancer and DCIS $(12,35)$. In accordance with National Comprehensive Cancer Network (NCCN) Guidelines, no sentinel biopsy is required in pure DCIS positive specimen when breast conservative surgery or mastectomy is scheduled. NCCN Guidelines support mastectomy with or without sentinel biopsy and reconstruction (36). However, when deciding on a patient's suitability for NSM we suggest multidisciplinary oncological consultation and compliance with local protocols: the focus of this study is the safety of the surgical technique regarding the incidence of necrosis.

Preshaping of the breast has the additional advantage of providing a dermoglandular supply to the NAC in a first stage $(8,9)$. This delay allows complete circumareolar dermal neovascularization to the NAC before a NSM is performed a few months later. As Alperovich (5) and Vaughn (6) described, the NAC perfusion in the second stage relies on dermal reperfusion through the circumareolar scar.

The tissue expander can be safely placed in the same procedure as the inferior pedicle breast reduction $(13,37)$. The internal thoracic artery is the main and constant contributor of blood to the NAC by means of its perforating branches 1 to 4 and anterior intercostal branches 4 to 6 . The most important are the branches originating from intercostal spaces 3 and 4 . The anterior intercostal branches 4 to 6 run from the medial costochondral rib junction through the pectoral muscle into the inferomedial pedicle. Secondarily it receives lateral mammary branches from the lateral thoracic artery that form an anastomotic ring with the internal thoracic branches superior and inferior of NAC (14). 
In addition, there is random vascularization in the lower glandular part of the pedicle, which may be provided by the lower intercostal branches $(14,38)$. However, Palmer and Taylor identify fixed skin areas around the perimeter of the pectoralis major muscle and the submammary fold. Major cutaneous perforators emerge in these areas, referred to as hypervascular zones (39).

A reduction in NAC vascular compromise is achieved in delayed prosthetic procedures by using an adjustable device: inflation starts when the wounds are completely healed. Even in the event of wound dehiscence (due to insufficient dermal vascularization), the expander is completely covered by the muscle flap. This coverage also needs to be able to support the weight of a larger prosthesis. This is less of a problem when an expander is gently inflated over time. Staged inflation will diminish the vascular stress of the mastectomy skin flaps and NAC. The capsule formed around the expander will create an additional coverage for the prosthesis, as well as an extra lower pole support. Expansion itself also works as an adjuvant inducing increased blood flow to the overlying skin $(40,41)$.

Preshaping of the implant pocket with capsule formation creates complete autologous implant coverage, including the lower lateral pole. Salibian recently advocated the twostage suprapectoral placement of the expander/prosthesis, especially in larger ptotic breasts, as this will reduce skin tension by contraction of the surrounding capsule (42). However, a thicker implant coverage has less chance in upper pole rippling: the preshaped pocket will allow easier a larger and higher implant creating less upper pole emptiness. The capsule of the expander acts as a hammock supporting the lower prosthesis pole. The same hammock can be created by an acellular dermal matrix (ADM) (43). Therefore, using an ADM can be a helpful tool in the reconstruction of the implant pocket. Stress yielding of myofibroblasts will diminish late capsule contraction. In addition, the slow repopulation of the ADM will delay the inflammatory response and diminish late capsular contraction (40,41). Gravina's meta-analysis supports the finding of ADM associated decreased capsular contracture rates, citing the incidence of capsular contracture with ADMs at $0.6 \%$ by a pooled analysis of 16 studies (42). Breast reduction skin flaps are random flaps, supplied by intercostal branches (2 to 6) of the internal thoracic artery as well as branches of the lateral thoracic artery (43): hypoperfusion can be noticed at their most distal flap end (inverted $\mathrm{T}$ point). However, poor vascular supply together with an ADM may be attractive for bacterial growth. It might be more prudent in larger breasts to use only skin expanders, with or without ADM-coverage, rather than an immediate prosthesis. Gradual inflation causes less skin flap traction. The absence of an ADM however decreases the risk of prosthesis infection in the second stage and also avoids a major cost $(44,45)$.

One patient reports implant-related discomfort. Our study patients are not routinely checked for breast animation deformity (BAD), only when this is causing discomfort. However, we know that in reconstructive patients $\mathrm{BAD}$ is reported up to $80 \%$ with moderate to severe deformity $(46,47)$. Further long-term outcome study will show BAD-severity of our reported technique.

Staged NSM avoids extra donor-site scars. This staged procedure will not preclude any type of autologous reconstruction in the future. In the event of a tertiary autologous reconstruction as described in one patient, the preshaped breast allows to maintain NAC position without an increased risk of necrosis (48).

\section{Conclusions}

In our study, preshaping of the large breast in a delayed NSM creates the ideal anatomical criteria for a reliable necrosis-free two-stage expander-to-prosthesis reconstruction. Nipple delay decreases necrosis rates in a staged procedure within an oncologically acceptable period. Preshaping of the breast pocket improves both prosthesis position and prosthesis coverage. Without the use of an $\mathrm{ADM}$ the expander capsule provides complete coverage while supporting the lower prosthesis pole as a hammock. It is wise to reconsider performing a SSM in smoking patients. The elimination of significant risk factors will reduce important postoperative complications, such as necrosis and infection. In our department the presented technique is the standard of care for large or ptotic breasts in high breast cancer risk patients or in peripheral early stage breast cancer patients with a multidisciplinary agreed, oncological indication for NSM who are reluctant to have an autologous reconstruction because of donor site scars or because of the length of surgery.

\section{Acknowledgments}

The manuscript was presented at the Annual Meeting of the European Association of Plastic Surgery (EURAPS), Helsinki, Finland on May 25th, 2019.

Funding: None. 


\section{Footnote}

Reporting Checklist: The authors have completed the STROBE reporting checklist. Available at https:// gs.amegroups.com/article/view/10.21037/gs-21-734/rc

Data Sharing Statement: Available at https://gs.amegroups. com/article/view/10.21037/gs-21-734/dss

Peer Review File: Available at https://gs.amegroups.com/ article/view/10.21037/gs-21-734/prf

Conflicts of Interest: All authors have completed the ICMJE uniform disclosure form (available at https://gs.amegroups. com/article/view/10.21037/gs-21-734/coif). The authors have no conflicts of interest to declare.

Ethical Statement: The authors are accountable for all aspects of the work in ensuring that questions related to the accuracy or integrity of any part of the work are appropriately investigated and resolved. The Ethics Committee of the Antwerp University Hospital, Antwerp, Belgium approved this research (19/26/314). Patients gave their written informed consent to participate in the study, and for publication of photos. The study complied with the principles of the Declaration of Helsinki (as revised in 2013).

Open Access Statement: This is an Open Access article distributed in accordance with the Creative Commons Attribution-NonCommercial-NoDerivs 4.0 International License (CC BY-NC-ND 4.0), which permits the noncommercial replication and distribution of the article with the strict proviso that no changes or edits are made and the original work is properly cited (including links to both the formal publication through the relevant DOI and the license). See: https://creativecommons.org/licenses/by-nc-nd/4.0/.

\section{References}

1. Palmieri B, Baitchev G, Grappolini S, et al. Delayed nipple-sparing modified subcutaneous mastectomy: rationale and technique. Breast J 2005;11:173-8.

2. Jensen JA, Lin JH, Kapoor N, et al. Surgical delay of the nipple-areolar complex: a powerful technique to maximize nipple viability following nipple-sparing mastectomy. Ann Surg Oncol 2012;19:3171-6.

3. Jolie A. My medical choice. New York: The New York
Times, 2013:A25.

4. Spear SL, Rottman SJ, Seiboth LA, et al. Breast reconstruction using a staged nipple-sparing mastectomy following mastopexy or reduction. Plast Reconstr Surg 2012;129:572-81.

5. Alperovich M, Tanna N, Samra F, et al. Nipple-sparing mastectomy in patients with a history of reduction mammaplasty or mastopexy: how safe is it? Plast Reconstr Surg 2013;131:962-7.

6. Vaughn CJ, Peled AW, Esserman LJ, et al. Feasibility of Performing Total Skin-Sparing Mastectomy in Patients With Prior Circumareolar Mastopexy or Reduction Mammoplasty Incisions. Ann Plast Surg 2013. [Epub ahead of print]. doi: 10.1097/SAP.0b013e3182977904.

7. Schwartz JC, Skowronksi PP. Surgical Delay Facilitates Pedicled Nipple-sparing Mastectomy and Reconstruction in the Ptotic Patient. Plast Reconstr Surg Glob Open 2016;4:e735.

8. Tondu T, Thiessen F, Tjalma WA. Prophylactic Bilateral Nipple-sparing Mastectomy and a Staged Breast Reconstruction Technique: Preliminary Results. Breast Cancer (Auckl) 2016;10:185-9.

9. Gunnarsson GL, Bille C, Reitsma LC, et al. Prophylactic Nipple-Sparing Mastectomy and Direct-to-Implant Reconstruction of the Large and Ptotic Breast: Is Preshaping of the Challenging Breast a Key to Success? Plast Reconstr Surg 2017;140:449-54.

10. Tondu T, Hubens G, Tjalma WA, et al. Breast reconstruction after nipple-sparing mastectomy in the large and/or ptotic breast: A systematic review of indications, techniques, and outcomes. J Plast Reconstr Aesthet Surg 2020;73:469-85.

11. Spear SL, Willey SC, Feldman ED, et al. Nipple-sparing mastectomy for prophylactic and therapeutic indications. Plast Reconstr Surg 2011;128:1005-14.

12. Weber WP, Haug M, Kurzeder C, et al. Oncoplastic Breast Consortium consensus conference on nipple-sparing mastectomy. Breast Cancer Res Treat 2018;172:523-37.

13. Beale EW, Ramanadham S, Harrison B, et al. Achieving predictability in augmentation mastopexy. Plast Reconstr Surg 2014;133:284e-92e.

14. van Deventer PV, Graewe FR. The Blood Supply of the Breast Revisited. Plast Reconstr Surg 2016;137:1388-97.

15. Bille C, Dalaei F, Thomsen JB. Identifying the dissection plane for mastectomy-description and visualization of our technique. Gland Surg 2019;8:S276-80.

16. Torresan RZ, dos Santos CC, Okamura H, et al. Evaluation of residual glandular tissue after skin-sparing 
mastectomies. Ann Surg Oncol 2005;12:1037-44.

17. van Verschuer VM, Maijers MC, van Deurzen CH, et al. Oncological safety of prophylactic breast surgery: skinsparing and nipple-sparing versus total mastectomy. Gland Surg 2015;4:467-75.

18. Lyman GH, Somerfield MR, Bosserman LD, et al. Sentinel Lymph Node Biopsy for Patients With EarlyStage Breast Cancer: American Society of Clinical Oncology Clinical Practice Guideline Update. J Clin Oncol 2017;35:561-4.

19. Kroll SS, Ames F, Singletary SE, et al. The oncologic risks of skin preservation at mastectomy when combined with immediate reconstruction of the breast. Surg Gynecol Obstet 1991;172:17-20.

20. Larson DL, Basir Z, Bruce T. Is oncologic safety compatible with a predictably viable mastectomy skin flap? Plast Reconstr Surg 2011;127:27-33.

21. Davies K, Allan L, Roblin P, et al. Factors affecting postoperative complications following skin sparing mastectomy with immediate breast reconstruction. Breast 2011;20:21-5.

22. Regolo L, Ballardini B, Gallarotti E, et al. Nipple sparing mastectomy: an innovative skin incision for an alternative approach. Breast 2008;17:8-11.

23. Rusby JE, Gui GP. Nipple-sparing mastectomy in women with large or ptotic breasts. J Plast Reconstr Aesthet Surg 2010;63:e754-5.

24. Chirappapha P, Petit JY, Rietjens M, et al. Nipple sparing mastectomy: does breast morphological factor related to necrotic complications? Plast Reconstr Surg Glob Open 2014;2:e99.

25. Robertson SA, Rusby JE, Cutress RI. Determinants of optimal mastectomy skin flap thickness. Br J Surg 2014;101:899-911.

26. Algaithy ZK, Petit JY, Lohsiriwat V, et al. Nipple sparing mastectomy: can we predict the factors predisposing to necrosis? Eur J Surg Oncol 2012;38:125-9.

27. Wapnir I, Dua M, Kieryn A, et al. Intraoperative imaging of nipple perfusion patterns and ischemic complications in nipple-sparing mastectomies. Ann Surg Oncol 2014;21:100-6.

28. Komorowska-Timek E, Gurtner GC. Intraoperative perfusion mapping with laser-assisted indocyanine green imaging can predict and prevent complications in immediate breast reconstruction. Plast Reconstr Surg 2010;125:1065-73.

29. Gorai K, Inoue K, Saegusa N, et al. Prediction of Skin Necrosis after Mastectomy for Breast Cancer Using Indocyanine Green Angiography Imaging. Plast Reconstr
Surg Glob Open 2017;5:e1321.

30. Burnier P, Niddam J, Bosc R, et al. Indocyanine green applications in plastic surgery: A review of the literature. J Plast Reconstr Aesthet Surg 2017;70:814-27.

31. Wijayanayagam A, Kumar AS, Foster RD, et al. Optimizing the total skin-sparing mastectomy. Arch Surg 2008;143:38-45; discussion 45.

32. Laronga C, Kemp B, Johnston D, et al. The incidence of occult nipple-areola complex involvement in breast cancer patients receiving a skin-sparing mastectomy. Ann Surg Oncol 1999;6:609-13.

33. Voltura AM, Tsangaris TN, Rosson GD, et al. Nipplesparing mastectomy: critical assessment of 51 procedures and implications for selection criteria. Ann Surg Oncol 2008;15:3396-401.

34. Endara M, Chen D, Verma K, et al. Breast reconstruction following nipple-sparing mastectomy: a systematic review of the literature with pooled analysis. Plast Reconstr Surg 2013;132:1043-54.

35. Benediktsson KP, Perbeck L. Survival in breast cancer after nipple-sparing subcutaneous mastectomy and immediate reconstruction with implants: a prospective trial with 13 years median follow-up in 216 patients. Eur J Surg Oncol 2008;34:143-8.

36. National Comprehensive Cancer Network. Clinical Practice Guidelines in Oncology. Updates in Version 4.2021 of the NCCN Guidelines for Breast Cancer: DCIS-1. 2021. Available online: https://www.nccn.org/ professionals/physician_gls/pdf/breast.pdf (accessed 16 June 2021).

37. Jensen JA, Giuliano AE. The Hybrid Delay: A New Approach for Nipple-sparing Mastectomy in Macromastia. Plast Reconstr Surg Glob Open 2020;8:e2940.

38. di Summa PG, Oranges CM, Watfa W, et al. Systematic review of outcomes and complications in nonimplantbased mastopexy surgery. J Plast Reconstr Aesthet Surg 2019;72:243-72.

39. Palmer JH, Taylor GI. The vascular territories of the anterior chest wall. Br J Plast Surg 1986;39:287-99.

40. Hallberg H, Rafnsdottir S, Selvaggi G, et al. Benefits and risks with acellular dermal matrix (ADM) and mesh support in immediate breast reconstruction: a systematic review and meta-analysis. J Plast Surg Hand Surg 2018;52:130-47.

41. Namnoum JD, Moyer HR. The role of acellular dermal matrix in the treatment of capsular contracture. Clin Plast Surg 2012;39:127-36.

42. Salibian AH, Harness JK, Mowlds DS. Staged 
Suprapectoral Expander/Implant Reconstruction without Acellular Dermal Matrix following Nipple-Sparing Mastectomy. Plast Reconstr Surg 2017;139:30-9.

43. Gunnarsson GL, Heidemann LN, Bille C, et al. Nipple sparing mastectomy and the evolving direct to implant breast reconstruction. Gland Surg 2018;7:267-72.

44. Chun YS, Verma K, Rosen H, et al. Implant-based breast reconstruction using acellular dermal matrix and the risk of postoperative complications. Plast Reconstr Surg 2010;125:429-36.

45. Lee KT, Mun GH. Updated Evidence of Acellular Dermal Matrix Use for Implant-Based Breast Reconstruction: A

Cite this article as: Tondu T, Thiessen F, Hubens G, Tjalma W, Blondeel P, Verhoeven V. Delayed two-stage nipple sparing mastectomy and simultaneous expander-to-implant reconstruction of the large and ptotic breast. Gland Surg 2022;11(3):524-534. doi: 10.21037/gs-21-734
Meta-analysis. Ann Surg Oncol 2016;23:600-10.

46. Nigro LC, Blanchet NP. Animation Deformity in Postmastectomy Implant-Based Reconstruction. Plast Reconstr Surg Glob Open 2017;5:e1407.

47. Kim JYS, Davila AA, Persing S, et al. A meta-analysis of human acellular dermis and submuscular tissue expander breast reconstruction. Plast Reconstr Surg 2012;129:28-41.

48. DellaCroce FJ, Blum CA, Sullivan SK, et al. NippleSparing Mastectomy and Ptosis: Perforator Flap Breast Reconstruction Allows Full Secondary Mastopexy with Complete Nipple Areolar Repositioning. Plast Reconstr Surg 2015;136:1e-9e. 